\title{
Nickel don't care about no air
}

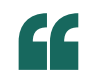

We are targeting

a balance between stability and reactivity gु
Nickel catalysts have risen to prominence in organic chemistry because they are potentially more sustainable than palladium catalysts and have a different substrate scope. $\mathrm{Ni}^{0}$ phosphines are particularly electron-rich, such that they readily undergo oxidative addition, a key step in many catalytic cycles. These complexes can be generated from a phosphine ligand and a labile $\mathrm{Ni}^{0}$ precatalyst, but the latter typically takes the form of an alkene complex that is neither thermally nor aerobically stable. After lying dormant for half a century, the venerable complex [Ni(COD) (DQ)] (COD = 1,5-cyclooctadiene; $\mathrm{DQ}=$ duroquinone) has been reawakened by Keary Engle and colleagues, who now describe in Angewandte Chemie International Edition practical syntheses and catalytic applications of this robust precatalyst.

The homoleptic $18 \mathrm{e}^{-}$complex $\left[\mathrm{Ni}(\mathrm{COD})_{2}\right]$ is the archetypical

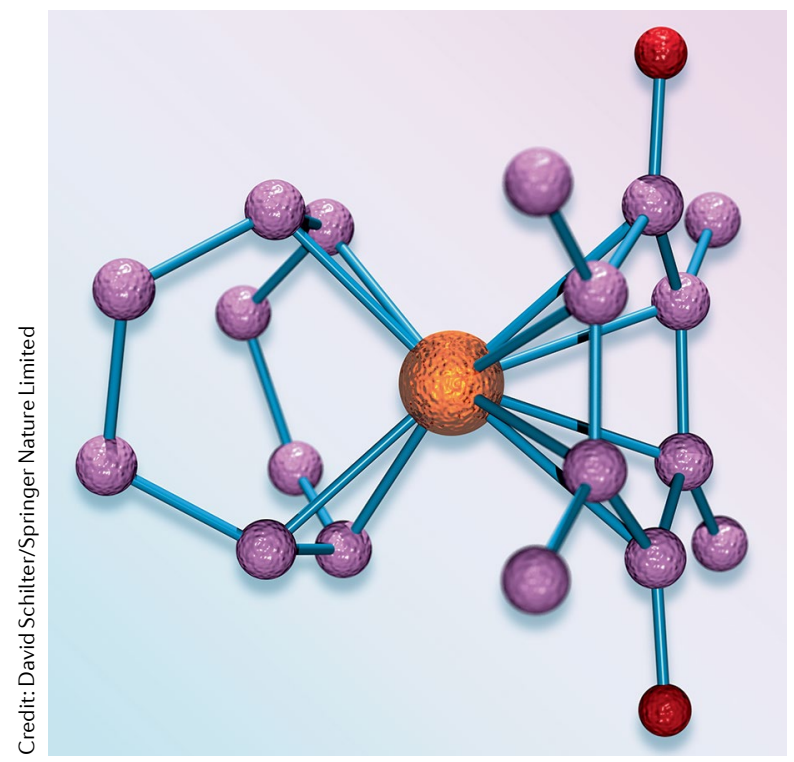

precatalyst as its $\pi$-acceptor alkene ligands stabilize low-valent Ni but can nevertheless be displaced by strong $\sigma$-donors such as phosphines to afford catalytically active electron-rich species. Yet $\left[\mathrm{Ni}(\mathrm{COD})_{2}\right]$ is not cheap and cannot persist outside a freezer or in air, so chemists have sought a more practical $\mathrm{Ni}^{0}$ source. It is non-trivial to engineer a complex to be more easily handled yet maintain its lability, but Engle's team tackled this by converting $\left[\mathrm{Ni}(\mathrm{COD})_{2}\right]$ to heteroleptic species that feature one COD ligand and a strongly $\pi$-acidic alkene co-ligand - systems in which $\mathrm{Ni}^{0}$ should be electron-poor and resist $\mathrm{O}_{2}$ attack. Monoalkene co-ligands did not afford aerobically stable complexes, but quinones proved ideal in that they have two alkene groups and are strong $\pi$-acids. In this way, the team came across [Ni(COD)(DQ)], a complex first prepared in 1962 from the highly toxic and volatile $\left[\mathrm{Ni}(\mathrm{CO})_{4}\right]$. The air stability of $[\mathrm{Ni}(\mathrm{COD})(\mathrm{DQ})]$ may stem from steric protection and strong $\pi$-backbonding, which is evident from a lowering of the duroquinone $\mathrm{C}=\mathrm{O}$ stretching frequencies upon ligation.

Notwithstanding its thermal and aerobic stability, [Ni(COD) (DQ)] retains much of the reactivity of $\left[\mathrm{Ni}(\mathrm{COD})_{2}\right]$. Combining the $[\mathrm{Ni}(\mathrm{COD})(\mathrm{DQ})]$ precatalyst with $\sigma$-donors such as $\mathrm{PPh}_{3}$ and $\mathrm{Ph}_{2} \mathrm{P}\left(\mathrm{CH}_{2}\right)_{3} \mathrm{PPh}_{2}$ affords putative $\mathrm{Ni}^{0}$ phosphines that catalyse reactions like the Suzuki-Miyaura coupling of aryls/heteroaryls and borylation of 4-(trifluoromethyl)chlorobenzene with pinacolborane. The new conditions afford yields approaching those obtained with the precatalyst $\left\{\mathrm{Ni}\left[1,1^{\prime}\right.\right.$-bis(diphenylphosphino) ferrocene](cinnamyl)Cl\} or by combining phosphines with $\left[\mathrm{Ni}(\mathrm{COD})_{2}\right]$ or the air-stable $16 \mathrm{e}^{-}$ tris(alkene) $\left[\mathrm{Ni}\left({ }^{\mathrm{F}} \mathrm{stb}\right)_{3}\right]\left({ }^{\mathrm{F}} \mathrm{stb}=4,4^{\prime}-\right.$ bis(trifluoromethyl)-trans-stilbene) described in a recent Nature Catalysis article by Josep Cornella and co-workers. The coordinatively unsaturated $\mathrm{Ni}^{0}$ centre in $\left[\mathrm{Ni}\left({ }^{\mathrm{F}} \mathrm{stb}\right)_{3}\right]$ enjoys steric protection but can release its monoalkenes to afford catalytically active species - in some cases even without the addition of phosphines. In all, $\left[\mathrm{Ni}\left({ }^{\mathrm{F}} \mathrm{stb}\right)_{3}\right]$ is slightly more reactive than $[\mathrm{Ni}(\mathrm{COD})(\mathrm{DQ})]$, while the latter has the advantage of being indefinitely stable to air and moisture at room temperature. In addition to determining how the DQ precatalyst is activated, "we are also interested in using external stimuli to effect ligand exchange," notes Engle.

Both $\left[\mathrm{Ni}\left({ }^{\mathrm{F}} \mathrm{stb}\right)_{3}\right]$ and $[\mathrm{Ni}(\mathrm{COD})$ (DQ)] are available through practical and economical syntheses from the $\mathrm{Ni}^{\mathrm{II}}$ source $\left[\mathrm{Ni}_{3}\right.$ (acetylacetonato) ${ }_{6}$, the respective olefinic ligands and a reductant $\left(\mathrm{AlEt}_{3}\right.$ and $\left({ }^{i} \mathrm{Bu}_{2} \mathrm{AlH}\right)_{2}$, respectively).

Such air-stable precatalysts can be handled outside an inert-atmosphere glovebox, such that one can rapidly screen ligands, substrates and reaction conditions. The methods are accessible and scalable, so when a successful combination is found it may be translated to an industrial setting. "We are targeting a balance between stability and reactivity to prepare tailored catalysts for specific user needs," concludes Engle.

\section{David Schilter}

ORIGINAL ARTICLE Tran, V. et al. Ni(COD)(DQ): an air-stable 18-electron $\mathrm{Ni}(0)$-olefin precatalyst. Angew.Chem. Int. Ed. https://doi.org/10.1002/ anie.202000124 (2020)

RELATED ARTICLE Nattmann, L. et al. An air-stable binary Ni(0)-olefin catalyst. Nat. Catal. 3, 6-13 (2020) 